\title{
Title
}

\section{Projecting the seasonality of endemic COVID-19}

\section{Authors}

Jeffrey P. Townsend ${ }^{1,2,3,4^{*}}$, April D. Lamb ${ }^{5}$, Hayley B. Hassler ${ }^{1}$, Pratha Sah $^{6}$, Aia Alvarez Nishio ${ }^{7}$, Cameron Nguyen ${ }^{5}$, Alison P. Galvani ${ }^{6}$, and Alex Dornburg ${ }^{5}$

\section{Affiliations}

${ }^{1}$ Department of Biostatistics, Yale School of Public Health; New Haven, Connecticut, USA

${ }^{2}$ Department of Ecology and Evolutionary Biology, Yale University; New Haven, Connecticut, USA

${ }^{3}$ Program in Computational Biology and Bioinformatics, Yale University; New Haven, Connecticut, USA

${ }^{4}$ Program in Microbiology, Yale University; New Haven, Connecticut, USA

${ }^{5}$ Department of Bioinformatics and Genomics, University of North Carolina at Charlotte;

Charlotte, $N C$

${ }^{6}$ Center for Infectious Disease Modeling and Analysis, Yale University; New Haven, Connecticut 06510, USA

${ }^{7}$ Yale College; New Haven, Connecticut 06510, USA

${ }^{*}$ Corresponding author 
medRxiv preprint doi: https://doi.org/10.1101/2022.01.26.22269905; this version posted January $28,2022$. The copyright holder for this preprint (which was not certified by peer review) is the author/funder, who has granted medRxiv a license to display the preprint in perpetuity.

It is made available under a CC-BY 4.0 International license

Successive waves of infection by SARS-CoV-2 have left little doubt that this virus will transition to an endemic disease ${ }^{1,2}$. Projections of the endemic seasonality of SARS-CoV-2 transmission are crucial to informed public health policy ${ }^{3}$. Such projections are not only essential to well-timed interventions and the preparation of healthcare systems for synchronous surges with other respiratory viruses ${ }^{4}$, but also to the elimination of seasonality as a confounder in the identification of surges that are occurring due to viral evolution, changes in host immunity, or other non-seasonal factors. However, the less than two-year duration of SARS-CoV-2 circulation, pandemic dynamics, and heterogeneous implementation of interventions have grievously complicated evaluations of its seasonality ${ }^{5}$. Here we estimate the impending endemic seasonality of SARS-CoV-2 in global population centers via a novel phylogenetic ancestral and descendent states $\operatorname{approach}^{6}$ that leverages long-term data on the incidence of circulating coronaviruses. Our results validate a major concern that endemic COVID-19 will typically surge coincident with other high-morbidity and -mortality respiratory virus infections such as influenza and $\mathrm{RSV}^{7}$. In temperate locales in the Northern Hemisphere, we identify spatiotemporal surges of incidences that range from October through January in New York to January through March in Yamagata, Japan. This knowledge of likely spatiotemporal surges of COVID-19 is fundamental to optimal timing of public health interventions that anticipate the impending endemicity of this disease and mitigate SARS-CoV-2 transmission.

The current COVID-19 pandemic has resulted in over 5.5 million deaths worldwide ${ }^{8}$. Sustained transmission is predicted to continue into the foreseeable future ${ }^{3,9}$, rendering COVID-19 into a global endemic disease ${ }^{1}$. Changes in case numbers have been observed in different regions and at different times during the last year; it is unclear whether these changes 
have been consequences of public health regulations, behavior change, the virulence evolution, or interactions of these factors under local environmental conditions ${ }^{5}$. Analyses of data on pandemic spread have also associated higher rates of infection and mortality with low UV light, low humidity, and temperature ${ }^{10,11}$. However, given the global variability in public health measures throughout the pandemic and the short duration since SARS-CoV-2 emergence, there is little applicable data upon which to directly determine the seasonality of the virus ${ }^{12}$. This absence of annual SARS-CoV-2 infection data without interventions has hampered efforts to determine COVID-19 seasonality and resulted in contradictory estimates of seasonal trends ${ }^{13-16}$. Therefore, an alternate approach to estimating the seasonality that will not be confounded by public health interventions or pandemic transmission dynamics is necessary for global preparation and pandemic policy decision-making.

Seasonality of SARS-CoV-2 can be inferred by analogy to the annual variation in transmission of other respiratory viruses, including multiple coronaviruses ${ }^{16-20}$. However, such analogies lack rigorous quantification. As an alternative to analogy, data on human-infecting coronavirus relatives of SARS-CoV-2 can be analyzed via a well-established quantitative comparative phylogenetic approach. This approach utilizes available trait data from close evolutionary relatives, the rate at which a trait evolves, and information on evolutionary divergences to estimate ancestral and descendent states ${ }^{21,22}$. Such evolutionary inference has already yielded crucial estimates of the durability of immunity against reinfection by SARS-CoV-2 ${ }^{6}$. Here we apply comparative phylogenetics to extensive long-term incidence data on other coronaviruses (HCoV-OC43, HCoV-NL63, HCoV-HKU1, HCoV-229E) across major population centers. This analysis provides an unconfounded means for estimation of the seasonal force of infection that is not dependent on isolation of interventions or identification of 
underlying mechanisms. Our projections of endemic SARS-CoV-2 seasonality are fundamental to the anticipation and optimization of public policy for high-risk periods and to the preparation of healthcare providers for localized surges.

\section{Results}

Our systematic review regarding seasonal patterns of endemic coronavirus incidence identified 14 studies that met the criteria of providing at least one year of data on at least three circulating human-infecting coronaviruses within a locale. These studies spanned three continents across the Northern Hemisphere (Table 1): North America (Datasets i \& ii), Europe (Datasets iii-vii), and Asia (Datasets viii-xiii). In temperate regions, endemic coronaviruses typically exhibited pronounced seasonality (Supplementary Figs. S1-S4).

For each location, we pruned the phylogeny of major coronavirus lineages from Townsend et al. ${ }^{6}$ to include only the endemic human-infecting coronaviruses with sample data and SARS-CoV-2 (Table 1, Fig. 1A). To generate maximum-likelihood estimates of the spatiotemporal incidences of SARS-CoV-2, we conducted analyses of ancestral and descendent states on the relative monthly incidences for each coronavirus (Fig. 1B-E). All four endemic coronaviruses contributed to our projection of the relative monthly incidence of SARS-CoV-2 (Fig. 1F). However, the late-diverging $\mathrm{HCoV}-\mathrm{OC} 43$ and $\mathrm{HCoV}-\mathrm{HKU} 1$ provide more phylogenetic information than the early-diverging HCoV-NL63 and HCoV-229E. Application of this evolutionary analysis to Trøndelag, Norway provides projections that late fall and winter months will exhibit significantly higher levels of SARS-CoV-2 incidence than summer and early fall months (Fig. 1F). 
This lower incidence in the summer and surrounding months is largely generalizable to much of the temperate Northern Hemisphere (Fig. 2). Specifically, significantly higher SARS-CoV-2 incidence is projected in late fall and winter months in New York City (Fig. 2A). A similar seasonality is projected for Tampere, Finland; Gothenburg and Stockholm in Sweden (Fig. 2B); as well as multiple locales in Asia, including Yamagata, Japan; Guangzhou, China; and South Korea (Fig. 2C). However, in each Northern Hemisphere continent, there are regional deviations from this seasonal pattern. In Denver, incidence is projected not to rise until the late winter, peaking in early Spring (Fig. 2A). Incidence in Amsterdam is similarly projected to decline in late spring. In contrast to Denver, incidence in Amsterdam rises earlier, during the late Fall (Fig. 2B). In Asia (Fig. 2C), incidence in Sarlahi, Nepal is projected to surge in early winter. In coastal, subtropical Hong Kong, the projected apex is in late fall, but monthly variation in incidence is muted across other seasons. Seasonality for tropical Nakhon Si Thammarat, Thailand is also projected to be muted relative to the temperate Northern Hemisphere locations, and the seasonality of incidence in the megalopolis of Beijing, China appears atypical with no distinct pattern. In all cases, these results were robust to the phylogenetic inference method, underlying molecular dataset, as well as the use of a chronogram or molecular evolutionary tree (Supplemental Figs. S5-S8).

\section{Discussion}

Here we analyzed monthly incidence data of the currently circulating endemic coronaviruses HCoV-NL63, -229E, -HKU1, and -OC43 to quantify seasonality of incidence of these viruses in regions that span a broad range of predominantly temperate localities across North America, Europe, and Asia. We conducted ancestral- and descendent-states analyses, 
projecting the seasonality of SARS-CoV-2 as it becomes endemic. Across much of the temperate Northern Hemisphere, SARS-CoV-2 can be expected to transition to a seasonal pattern of incidence that is high in late fall and winter months relative to late spring and summer. Our expected incidences through time also reveal geographic heterogeneity. This heterogeneity often manifested as a syncopation of the general northern hemispheric trend-a delay in rise to peak incidence, or a prolonged duration of higher levels of incidence relative to other areas. These temporal transmission patterns of SARS-CoV-2 provide fundamental insights for the determination of local public health policies, enabling preparedness and consequent mitigation of seasonal rises in incidence.

Several previous studies have taken on the challenge of predicting seasonality of SARS-CoV-2 based on direct analysis of incidence across seasons during the initial pandemic spread $^{23-25}$. During a zoonotic pandemic, out-of-phase emergence, regional variations in public health intervention, and stochastic pulses of local transmission can obscure the signature of seasonality from surveillance data ${ }^{12}$. Such concerns have made these analyses controversial ${ }^{26,27}$. To avoid such concerns, our analyses are based on multi-year endemic coronavirus incidence data and are not subject to the biases introduced by pandemic emergence and large-scale public health interventions. Results from our analysis are broadly consistent with the seasonal incidence trends observed for common human-infecting respiratory viruses in the northern hemisphere ${ }^{17}$.

Our results on the seasonality of SARS-CoV-2 impart expected incidence trends under endemic conditions. Through two alternative mechanisms, seasonality during its pandemic phase might be either greater or lesser than that expected during subsequent endemicity. On the one hand, the absence of previous exposure and a corresponding naive immune response that are associated with overall higher transmission in a pandemic have the potential to exacerbate peaks 
and troughs of transmission. In this context, seasonality can be further amplified by an overwhelmed and lagging public health response. As such, we could observe heightened seasonal differences in incidence relative to those seen during endemic spread, overlaid onto peaks and troughs caused by the out-of-phase emergence of pandemic disease ${ }^{28}$. On the other hand, the mechanisms that are driving the seasonality of coronavirus infections might exert slight influences that are magnified by pathogenic population dynamics year on year ${ }^{29}$. This resonation to convergence could underlie the observed seasonality of endemic coronaviruses

(Supplemental Figs. S1-S4). With a smaller forcing factor that is amplified by pathogen population dynamics, we would expect less seasonality for SARS-CoV-2 during pandemic spread than would be seen in its eventual endemic incidence. In this context, it is possible that not enough time has elapsed for endemic seasonality to be fully realized. Regardless of how the seasonal dynamics will manifest during this transition from its pandemic phase, our projections provide the expected endemic seasonality.

The seasonal coronavirus incidences in each location were collected in studies that monitored disease in distinct time spans and that may have been subject to a number of annually varying factors that can drive seasonal trends of respiratory infections. However, in many cases the incidences were obtained across multiple years of sampling. For example, the Stockholm, Sweden dataset ${ }^{30}$ encompasses 2,093 samples spanning a full decade. Consequently, it is unlikely that the month-to-month average incidences of these long-term datasets are substantially affected by anomalous years. Our results project a seasonal rhythm of SARS-CoV-2 that is broadly similar to the trends observed among many major human-infecting respiratory viruses ${ }^{31-33}$. This well-known seasonal trend toward greater respiratory incidence in the winter has been ascribed to a number of factors: temperature ${ }^{17,34-36}$, humidity ${ }^{37-40}$, solar ultraviolet 
radiation $^{41}$, and host behavior ${ }^{42}$. This trend is typically considered to be muted in the tropics, and reversed in the Southern Hemisphere ${ }^{33,43}$.

Expanded global surveillance of endemic seasonal coronavirus incidence-especially in the undersampled tropics and Southern Hemisphere-will enhance our understanding of coronavirus seasonality and facilitate preparedness. Denser sampling will enable more precise regional estimates. Sampling in the tropics would enable testing of the muted seasonality that appears there; sampling in the Southern Hemisphere would enable testing of a hypothesis of inverted seasonality compared to the Northern Hemisphere. This information would strengthen the foundation for forecasting not only endemic coronavirus seasonality, but also the seasonality of deadly emergent coronaviruses such as SARS-CoV-2.

Both public health interventions and evolutionary change impact whether the projected seasonality of SARS-CoV-2 will be observed. Transmission could be dampened by the acceleration of vaccination efforts around the world that, like other interventions, have the potential to disrupt erstwhile seasonality. Alternatively, the emergence of novel variants with elevated transmissibility — such as the Delta or Omicron variants ${ }^{44-46}$ - have the potential to thwart public health efforts and impact seasonal trends. Our results suggest that surges of novel COVID-19 variants will frequently coincide with other seasonal endemic respiratory viruses including influenza and respiratory syncytial virus ${ }^{47,48}$, potentially overwhelming healthcare facilities. Our projections affirm the need for systematic, prescient public health interventions that are cognizant of seasonality.

Foreknowledge of seasonality will enable informed, advanced public health messaging regarding seasons of high concern that could help to overcome barriers of nonadherence. Even with widespread vaccination efforts, SARS-CoV-2 is poised to join HCoV-229E, HCoV-NL63, 
$\mathrm{HCoV}-\mathrm{OC} 43$, and $\mathrm{HCoV}-\mathrm{HKU} 1$ as a circulating endemic coronavirus ${ }^{49}$. For epidemiological inferences such as seasonality that require long-term datasets, evolutionary biology can provide the theoretical foundation to deliver swift, quantitative, and rigorous insight into how novel threats to human health may behave. Our approach provides guidance for myriad public health decisions until the pandemic phase of SARS-CoV-2 spread has passed and collection of long-term data on endemic COVID-19 incidence becomes feasible. Moreover, in future research it can be broadly applied to seasonal data from any group of viruses to forecast the endemic traits of any emergent threat.

\section{Acknowledgments}

We thank Dan Warren for helpful discussion at the inception of this work.

\section{Authors contributions}

JPT and AD conceived the project and designed the study; ADL and CN performed literature review with contributions from $\mathrm{AD}$ and $\mathrm{AAN}$; ADL, CN, and AAN accessed, processed, and curated seasonality data; ADL performed formal analyses with guidance from AD, JPT, and HBH; AD, ADL, and JPT designed and implemented data visualizations; JPT and AD wrote the manuscript; ADL, PS, and AAN contributed components of the manuscript; and all authors reviewed the manuscript before submission. JPT and AD were responsible for the decision to submit the manuscript. All authors had full access to all the data in the study and had final responsibility for the decision to submit for publication. Data was verified by ADL.

\section{Competing Interests}


Authors declare that they have no competing interests.

\section{Funding}

National Science Foundation of the United States of America RAPID 2031204 (JPT and

AD), NSF Expeditions CCF 1918784 (JPT and APG), and support from the University of North Carolina, Charlotte to AD.

\section{Data and materials availability}

All data, inferred phylogenetic trees, imputed monthly proportions, and code underlying this study are publicly available on Zenodo: DOI:10.5281/zenodo.5274735.

\section{Supplementary Information}

Supplementary Information is available for this paper.

Correspondence and requests for materials should be addressed to Jeffrey P. Townsend.

\section{References cited}

1. Phillips, N. The coronavirus is here to stay — here's what that means. Nature 590, 382-384 (2021).

2. Antia, R. \& Halloran, M. E. Transition to endemicity: Understanding COVID-19. Immunity 54, 2172-2176 (2021).

3. Kissler, S. M., Tedijanto, C., Goldstein, E., Grad, Y. H. \& Lipsitch, M. Projecting the transmission dynamics of SARS-CoV-2 through the postpandemic period. Science $\mathbf{3 6 8}$, 
860-868 (2020).

4. Christen, P. et al. The J-IDEA Pandemic Planner: A Framework for Implementing Hospital Provision Interventions During the COVID-19 Pandemic. Med. Care 59, 371-378 (2021).

5. Carlson, C. J., Gomez, A. C. R., Bansal, S. \& Ryan, S. J. Misconceptions about weather and seasonality must not misguide COVID-19 response. Nat. Commun. 11, 4312 (2020).

6. Townsend, J. P. et al. The durability of immunity against reinfection by SARS-CoV-2: a comparative evolutionary study. Lancet Microbe 2, e666-e675 (2021).

7. Baker, R. E. et al. The impact of COVID-19 nonpharmaceutical interventions on the future dynamics of endemic infections. Proc. Natl. Acad. Sci. U. S. A. 117, 30547-30553 (2020).

8. John's Hopkins University Center for Systems Science and Engineering (CSSE). COVID-19 Dashboard. https://gisanddata.maps.arcgis.com/apps/opsdashboard/index.html\#/bda7594740fd4029942 $3467 \mathrm{~b} 48 \mathrm{e} 9 \mathrm{ecf6}$.

9. World Health Organization. Coronavirus disease (COVID-19) Situation Report 148.

10. Liu, X. et al. The role of seasonality in the spread of COVID-19 pandemic. Environ. Res. 195, $110874(2021)$.

11. Merow, C. \& Urban, M. C. Seasonality and uncertainty in global COVID-19 growth rates. Proc. Natl. Acad. Sci. U. S. A. 117, 27456-27464 (2020).

12. Tobias, A., Madaniyazi, L., Ng, C. F. S., Seposo, X. \& Hashizume, M. Can SARS-CoV-2 Global Seasonality be Determined After One Year of Pandemic? Environ Epidemiol 5, e146 (2021).

13. Jamil, T., Alam, I., Gojobori, T. \& Duarte, C. M. No Evidence for Temperature-Dependence of the COVID-19 Epidemic. Front Public Health 8, 436 (2020). 
14. Rouen, A., Adda, J., Roy, O., Rogers, E. \& Lévy, P. COVID-19: relationship between atmospheric temperature and daily new cases growth rate. Epidemiol. Infect. 148, e184 (2020).

15. Smit, A. J. et al. Winter Is Coming: A Southern Hemisphere Perspective of the Environmental Drivers of SARS-CoV-2 and the Potential Seasonality of COVID-19. Int. J. Environ. Res. Public Health 17, (2020).

16. Yap, T. F., Liu, Z., Shveda, R. A. \& Preston, D. J. A predictive model of the temperature-dependent inactivation of coronaviruses. Appl. Phys. Lett. 117, 060601 (2020).

17. Li, Y., Wang, X. \& Nair, H. Global Seasonality of Human Seasonal Coronaviruses: A Clue for Postpandemic Circulating Season of Severe Acute Respiratory Syndrome Coronavirus 2? The Journal of infectious diseases vol. 222 1090-1097 (2020).

18. Lagacé-Wiens, P., Bullard, J., Cole, R. \& Van Caeseele, P. Seasonality of coronaviruses and other respiratory viruses in Canada: Implications for COVID-19. Can. Commun. Dis. Rep. 47, 132-138 (2021).

19. Edridge, A. W. D. et al. Seasonal coronavirus protective immunity is short-lasting. Nat. Med. 26, 1691-1693 (2020).

20. Aldridge, R. W. et al. Seasonality and immunity to laboratory-confirmed seasonal coronaviruses (HCoV-NL63, HCoV-OC43, and HCoV-229E): results from the Flu Watch cohort study. Wellcome Open Res 5, 52 (2020).

21. Schluter, D., Price, T., Mooers, A. Ø. \& Ludwig, D. LIKELIHOOD OF ANCESTOR STATES IN ADAPTIVE RADIATION. Evolution 51, 1699-1711 (1997).

22. Goolsby, E. W., Bruggeman, J. \& Ané, C. Rphylopars: fast multivariate phylogenetic comparative methods for missing data and within-species variation. Methods Ecol. Evol. 8, 
22-27 (2017).

23. Araújo, M. B. \& Naimi, B. Spread of SARS-CoV-2 Coronavirus likely constrained by climate. doi:10.1101/2020.03.12.20034728.

24. Bajaj, P. \& Arya, P. C. Evolution and spread of SARS-CoV-2 likely to be affected by climate. doi:10.1101/2020.06.18.147074.

25. Baker, R. E., Yang, W., Vecchi, G. A., Metcalf, C. J. E. \& Grenfell, B. T. Assessing the influence of climate on wintertime SARS-CoV-2 outbreaks. Nat. Commun. 12, 846 (2021).

26. Carlson, C. J., Chipperfield, J. D., Benito, B. M., Telford, R. J. \& O’Hara, R. B. Species distribution models are inappropriate for COVID-19. Nat Ecol Evol 4, 770-771 (2020).

27. Carlson, C. J., Chipperfield, J. D., Benito, B. M., Telford, R. J. \& O’Hara, R. B. Don’t gamble the COVID-19 response on ecological hypotheses. Nature Ecology \& Evolution vol. 4 1155-1155 (2020).

28. Lewnard, J. A. \& Townsend, J. P. Climatic and evolutionary drivers of phase shifts in the plague epidemics of colonial India. Proc. Natl. Acad. Sci. U. S. A. 113, 14601-14608 (2016).

29. Katriel, G. \& Stone, L. Attack rates of seasonal epidemics. Mathematical Biosciences vol. 235 56-65 (2012).

30. Neher, R. A., Dyrdak, R., Druelle, V., Hodcroft, E. B. \& Albert, J. Potential impact of seasonal forcing on a SARS-CoV-2 pandemic. Swiss Med. Wkly 150, w20224 (2020).

31. Tamerius, J. et al. Global influenza seasonality: reconciling patterns across temperate and tropical regions. Environ. Health Perspect. 119, 439-445 (2011).

32. Tang, J. W. et al. Global epidemiology of non-influenza RNA respiratory viruses: data gaps and a growing need for surveillance. The Lancet Infectious Diseases vol. 17 e320-e326 
(2017).

33. Li, Y. et al. Global patterns in monthly activity of influenza virus, respiratory syncytial virus, parainfluenza virus, and metapneumovirus: a systematic analysis. Lancet Glob Health 7, e1031-e1045 (2019).

34. Azziz Baumgartner, E. et al. Seasonality, timing, and climate drivers of influenza activity worldwide. J. Infect. Dis. 206, 838-846 (2012).

35. Mofijur, M., Fattah, I. M. R., Saiful Islam, A. B., Ashrafur Rahman, S. M. \& Chowdhury, M. A. Relationship between Climate Variables and New Daily COVID-19 Cases in Dhaka, Bangladesh. doi:10.20944/preprints202007.0699.v1.

36. Livadiotis, G. Statistical analysis of the impact of environmental temperature on the exponential growth rate of cases infected by COVID-19. doi:10.1101/2020.04.21.20072405.

37. Scafetta, N. Distribution of the SARS-CoV-2 Pandemic and Its Monthly Forecast Based on Seasonal Climate Patterns. Int. J. Environ. Res. Public Health 17, (2020).

38. Friel, S. Climate Change and the People's Health. (Small Books Big Ideas in Popul, 2019).

39. Lin, R., Wang, X. \& Huang, J. Do Weather Conditions Affect COVID-19 Epidemic? Evidence Based on Panel Data of Prefecture-level Administrative Regions in China. doi:10.21203/rs.3.rs-645202/v1.

40. Peci, A. et al. Effects of Absolute Humidity, Relative Humidity, Temperature, and Wind Speed on Influenza Activity in Toronto, Ontario, Canada. Appl. Environ. Microbiol. 85, (2019).

41. Choi, Y.-W., Tuel, A. \& Eltahir, E. A. B. On the Environmental Determinants of COVID-19 Seasonality. Geohealth 5, e2021GH000413 (2021).

42. Moriyama, M., Hugentobler, W. J. \& Iwasaki, A. Seasonality of Respiratory Viral 
Infections. Annu Rev Virol 7, 83-101 (2020).

43. Stensballe, L. G., Devasundaram, J. K. \& Simoes, E. A. Respiratory syncytial virus epidemics: the ups and downs of a seasonal virus. Pediatr. Infect. Dis. J. 22, S21-32 (2003).

44. Planas, D. et al. Reduced sensitivity of SARS-CoV-2 variant Delta to antibody neutralization. Nature 596, 276-280 (2021).

45. Campbell, F. et al. Increased transmissibility and global spread of SARS-CoV-2 variants of concern as at June 2021. Euro Surveill. 26, (2021).

46. Cameroni, E. et al. Broadly neutralizing antibodies overcome SARS-CoV-2 Omicron antigenic shift. Nature (2021) doi:10.1038/s41586-021-04386-2.

47. Bloom-Feshbach, K. et al. Latitudinal variations in seasonal activity of influenza and respiratory syncytial virus (RSV): a global comparative review. PLoS One 8, e54445 (2013).

48. Tang, J. W. et al. Where have all the viruses gone? Disappearance of seasonal respiratory viruses during the COVID-19 pandemic. Journal of Medical Virology vol. 93 4099-4101 (2021).

49. Veldhoen, M. \& Simas, J. P. Endemic SARS-CoV-2 will maintain post-pandemic immunity. Nat. Rev. Immunol. 21, 131-132 (2021).

50. Galanti, M. et al. Longitudinal active sampling for respiratory viral infections across age groups. Influenza Other Respi. Viruses 13, 226-232 (2019).

51. Dominguez, S. R., Robinson, C. C. \& Holmes, K. V. Detection of four human coronaviruses in respiratory infections in children: a one-year study in Colorado. J. Med. Virol. 81, 1597-1604 (2009).

52. Heimdal, I. et al. Human Coronavirus in Hospitalized Children With Respiratory Tract 
Infections: A 9-Year Population-Based Study From Norway. J. Infect. Dis. 219, 1198-1206 (2019).

53. Brittain-Long, R., Andersson, L.-M., Olofsson, S., Lindh, M. \& Westin, J. Seasonal variations of 15 respiratory agents illustrated by the application of a multiplex polymerase chain reaction assay. Scand. J. Infect. Dis. 44, 9-17 (2012).

54. Paloniemi, M., Lappalainen, S. \& Vesikari, T. Commonly circulating human coronaviruses do not have a significant role in the etiology of gastrointestinal infections in hospitalized children. J. Clin. Virol. 62, 114-117 (2015).

55. Kim, J.-M. et al. Nation-wide surveillance of human acute respiratory virus infections between 2013 and 2015 in Korea. J. Med. Virol. 90, 1177-1183 (2018).

56. Matoba, Y. et al. Detection of the human coronavirus 229E, HKU1, NL63, and OC43 between 2010 and 2013 in Yamagata, Japan. Jpn. J. Infect. Dis. 68, 138-141 (2015).

57. Zhang, S.-F. et al. Epidemiology characteristics of human coronaviruses in patients with respiratory infection symptoms and phylogenetic analysis of $\mathrm{HCoV}-\mathrm{OC} 43$ during 2010-2015 in Guangzhou. PLoS One 13, e0191789 (2018).

58. Uddin, S. M. I. et al. Burden and Risk Factors for Coronavirus Infections in Infants in Rural Nepal. Clin. Infect. Dis. 67, 1507-1514 (2018).

59. Ren, L. et al. Prevalence of human coronaviruses in adults with acute respiratory tract infections in Beijing, China. J. Med. Virol. 83, 291-297 (2011).

60. Lau, S. K. P. et al. Coronavirus HKU1 and other coronavirus infections in Hong Kong. J. Clin. Microbiol. 44, 2063-2071 (2006).

61. Suwannakarn, K. et al. Prevalence and genetic characterization of human coronaviruses in southern Thailand from July 2009 to January 2011. Southeast Asian J. Trop. Med. Public 
Health 45, 326-336 (2014).

Table 1. Datasets on seasonal coronavirus incidence

\begin{tabular}{|c|c|c|c|c|c|c|c|c|}
\hline \multirow[b]{2}{*}{ Dataset } & \multirow[b]{2}{*}{ Location } & \multirow[b]{2}{*}{ Dates } & \multirow[b]{2}{*}{ Sample } & \multicolumn{4}{|c|}{$\mathrm{HCoV}$ incidence } & \multirow[b]{2}{*}{ Reference } \\
\hline & & & & $229 \mathrm{E}$ & OC43 & NL63 & HKU1 & \\
\hline \multicolumn{9}{|c|}{ North America } \\
\hline $\mathrm{i}$ & $\begin{array}{l}\text { New York City, } \\
\text { USA }\end{array}$ & $\begin{array}{l}10 / 2016- \\
12 / 2018\end{array}$ & 122 & 31 & 48 & 15 & 28 & 50 \\
\hline ii & $\begin{array}{l}\text { Denver, } \\
\text { Colorado, USA }\end{array}$ & $\begin{array}{l}12 / 2004 \\
11 / 2005\end{array}$ & 84 & 11 & 34 & 37 & 2 & 51 \\
\hline \multicolumn{9}{|l|}{ Europe } \\
\hline iii & $\begin{array}{l}\text { Stockholm, } \\
\text { Sweden }\end{array}$ & $\begin{array}{l}1 / 2010- \\
2 / 2020\end{array}$ & 2,093 & 320 & 1,266 & 507 & $-^{\mathrm{a}}$ & 30 \\
\hline iv & $\begin{array}{l}\text { Trøndelag, } \\
\text { Norway }\end{array}$ & $\begin{array}{l}1 / 2007- \\
12 / 2014\end{array}$ & 263 & 16 & 113 & 84 & 50 & 52 \\
\hline $\mathrm{v}$ & $\begin{array}{l}\text { Gothenburg, } \\
\text { Sweden }\end{array}$ & $\begin{array}{l}11 / 2006- \\
10 / 2009\end{array}$ & 239 & 33 & 124 & 82 & $-^{\mathrm{a}}$ & 53 \\
\hline vi & $\begin{array}{l}\text { Amsterdam, } \\
\text { Netherlands }\end{array}$ & $\begin{array}{l}1985- \\
2011\end{array}$ & 101 & 38 & 30 & 25 & 8 & 19 \\
\hline vii & $\begin{array}{l}\text { Tampere, } \\
\text { Finland }\end{array}$ & $\begin{array}{l}\text { 9/2009- } \\
8 / 2011\end{array}$ & 52 & 13 & 13 & 15 & 11 & 54 \\
\hline \multicolumn{9}{|l|}{ Asia } \\
\hline viii & South Korea ${ }^{\mathrm{b}}$ & $\begin{array}{l}1 / 2010- \\
12 / 2012\end{array}$ & 1,568 & 153 & 871 & 544 & $-^{\mathrm{a}}$ & 55 \\
\hline ix & $\begin{array}{l}\text { Yamagata, } \\
\text { Japan }\end{array}$ & $\begin{array}{l}1 / 2010- \\
12 / 2014\end{array}$ & 388 & 40 & 94 & 154 & 100 & 56 \\
\hline $\mathrm{x}$ & $\begin{array}{l}\text { Guangzhou, } \\
\text { China }\end{array}$ & $\begin{array}{l}7 / 2010- \\
6 / 2015\end{array}$ & 293 & 49 & 177 & 44 & 23 & 57 \\
\hline $\mathrm{xi}$ & $\begin{array}{l}\text { Sarlahi, } \\
\text { Nepal }\end{array}$ & $\begin{array}{l}\text { 6/2011- } \\
5 / 2014\end{array}$ & 270 & 19 & 103 & 70 & 78 & 58 \\
\hline
\end{tabular}


medRxiv preprint doi: https://doi.org/10.1101/2022.01.26.22269905; this version posted January 28, 2022. The copyright holder for this preprint (which was not certified by peer review) is the author/funder, who has granted medRxiv a license to display the preprint in perpetuity.

It is made available under a CC-BY 4.0 International license.

\begin{tabular}{|c|c|c|c|c|c|c|c|c|}
\hline xii & $\begin{array}{l}\text { Beijing, } \\
\text { China }\end{array}$ & $\begin{array}{l}5 / 2005- \\
4 / 2009\end{array}$ & 87 & 15 & 50 & 8 & 14 & 59 \\
\hline xiii & $\begin{array}{l}\text { Hong Kong, } \\
\text { China }\end{array}$ & $\begin{array}{l}4 / 2014 \\
5 / 2015\end{array}$ & 87 & 4 & 53 & 17 & 13 & 60 \\
\hline xiv & $\begin{array}{l}\text { Nakhon Si } \\
\text { Thammarat, } \\
\text { Thailand }\end{array}$ & $\begin{array}{l}7 / 2009- \\
6 / 2010\end{array}$ & 32 & $-^{\mathrm{a}}$ & 22 & 9 & 1 & 61 \\
\hline
\end{tabular}

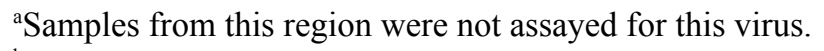

bationwide. 
medRxiv preprint doi: https://doi.org/10.1101/2022.01.26.22269905; this version posted January 28, 2022. The copyright holder for this preprint (which was not certified by peer review) is the author/funder, who has granted medRxiv a license to display the preprint in perpetuity.

It is made available under a CC-BY 4.0 International license.

\section{Figure legends}

Figure 1. Phylogenetic inference of relative monthly incidence of SARS-CoV-2 under endemic conditions. (A) Time tree based on the phylogenetic divergence of circulating human-infecting coronaviruses. Empirical relative monthly incidences of $\mathrm{HCoV}$ (B) -NL63, (C) -229E, (D) -HKU1, and (E) -OC43, and ancestral- and descendent-states analytical estimates of relative monthly incidences of SARS-CoV-2 in Trøndelag, Norway.

Figure 2. Ancestral- and descendent-states analytical estimates of the relative monthly incidence of SARS-CoV-2 under endemic conditions. (A) New York City and Denver, USA; (B) Amsterdam, Netherlands; Gothenburg and Stockholm, Sweden; Trøndelag, Norway; and Tampere, Finland; (C) Beijing, China; Sarlahi, Nepal; Guangzhou, China; Nakhon Si Thammarat, Thailand; Hong Kong, China; Yamagata, Japan; and South Korea (nationwide). 


\section{Materials and Methods}

\section{Study Design}

We performed a comparative evolutionary analysis on monthly verified cases of HCoV-NL63, $\mathrm{HCoV}-229 \mathrm{E}, \mathrm{HCoV}-\mathrm{HKU} 1$, and $\mathrm{HCoV}-\mathrm{OC} 43$ infection within populations across the globe. We applied ancestral and descendent states analyses on reconstructions of the evolutionary history of human-infecting coronaviruses to estimate the expected annual changes in cases at different geographic locales. These analyses provide a global-scale projection of the likely global changes of endemic seasonality for SARS-CoV-2.

\section{Data acquisition}

Phylogenetic tree topologies - Phylogenetic relationships of SARS-CoV-2 and the endemic human-infecting coronaviruses were based on data from 58 Alphacoronavirus, 105

Betacoronavirus, 11 Deltacoronavirus, and three Gammacoronavirus as analyzed in Townsend et al. ${ }^{6 ;}$ Fig. 1A. These estimates of the phylogenetic topology were consistent with previous hypotheses of evolutionary relationships among coronaviruses (62-66) and were congruent across multiple methods of inference with strong (100\% bootstrap) support for all nodes. Tree topologies were inferred by multiple maximum-likelihood (ML) analyses of the concatenated DNA sequence alignment, and results were robust to alternative phylogenetic likelihood search algorithms - IQ-TREE v2.0.6 (67) and RAxML v7.2.8 (68) — and to branch-length differences arising from different approaches to divergence time estimation-IQ-TREE v2.0.6 (67), Relative Times (RelTime; 69) in MEGA X v10.1.9 (70) and TreeTime v0.7.6 (71) — and to a potential history of recombination among or within genes, through phylogenetic analyses using an alignment of the putative non-recombining blocks (72). All trees from Townsend et al ${ }^{6}$ were pruned of SARS-CoV-1 and MERS-CoV branches because temporal trends of infection by these viruses reflect short-term outbreaks and not seasonal endemic circulation.

Seasonal infection data - We conducted a literature search using the PubMed and Google Scholar databases searching for terms related to coronavirus, seasonality, and the known seasonalendemic human-infecting coronaviruses (HCoV-NL63, HCoV-229E, HCoV-HKU1, and $\mathrm{HCoV}-\mathrm{OC} 43$ ). Searches were conducted in English between October 2020-August 2021, using the names of each coronavirus lineage as a key term in addition to all combinations of: coronavirus, seasonality, environmental, incidence, infection, prevalence, latitude, temperature, humidity, weather, global, cases_-with no language restrictions imposed. Seasonal infection data were extracted from published, peer-reviewed research papers that reported monthly or finer seasonal case data for three or more coronaviruses, spanning at least one year.

\section{Estimating the seasonality of SARS-CoV-2}

To estimate the seasonality of infections by SARS-CoV-2, we first extracted the average numbers 
of cases per month testing positive for HCoV-NL63, -229E, -HKU1, and -OC43 for each location. We scaled these case counts by the annual total to yield proportions of the cases sampled in each month. We then performed a phylogenetically informed ancestral and descendent states analysis, executing Rphylopars v0.2.12 (18) on the monthly proportions of cases to estimate the proportion of yearly infection by SARS-CoV-2 each month for each location, executing Rphylopars v0.2.12 (18) on the monthly proportions of cases. This approach takes known trait values (here, monthly proportions of cases for endemic coronaviruses) and applies a Brownian model of trait evolution and a phylogeny to estimate unobserved trait values for a taxon or taxa, providing best linear unbiased predictions that are mathematically equivalent to universal kriging (Gaussian process regression). Phylogenetic ancestral and descendent analyses were repeated across all topologies resulting from different inference approaches (molecular trees, relative phylogenetic chronograms, and non-recombinant alignment) to assess the impact of phylogenetic inference methods on our estimation of seasonality.

\section{References}

62. P. C. Y. Woo, S. K. P. Lau, C. S. F. Lam, C. C. Y. Lau, A. K. L. Tsang, J. H. N. Lau, R. Bai, J. L. L. Teng, C. C. C. Tsang, M. Wang, Others, Discovery of seven novel Mammalian and avian coronaviruses in the genus deltacoronavirus supports bat coronaviruses as the gene source of alphacoronavirus and betacoronavirus and avian coronaviruses as the gene source of gammacoronavirus and deltacoronavirus. J. Virol. 86, 3995-4008 (2012).

63. X. Fu, B. Fang, Y. Liu, M. Cai, J. Jun, J. Ma, D. Bu, L. Wang, P. Zhou, H. Wang, G. Zhang, Newly emerged porcine enteric alphacoronavirus in southern China: Identification, origin and evolutionary history analysis. Infect. Genet. Evol. 62, 179-187 (2018).

64. S. Pfefferle, S. Oppong, J. F. Drexler, F. Gloza-Rausch, A. Ipsen, A. Seebens, M. A. Müller, A. Annan, P. Vallo, Y. Adu-Sarkodie, T. F. Kruppa, C. Drosten, Distant relatives of severe acute respiratory syndrome coronavirus and close relatives of human coronavirus 229E in bats, Ghana. Emerg. Infect. Dis. 15, 1377-1384 (2009).

65. L. A. Sipulwa, J. R. Ongus, R. L. Coldren, W. D. Bulimo, Molecular characterization of human coronaviruses and their circulation dynamics in Kenya, 2009-2012. Virol. J. 13, 18 (2016).

66. Coronaviridae Study Group of the International Committee on Taxonomy of Viruses, The species Severe acute respiratory syndrome-related coronavirus: classifying 2019-nCoV and naming it SARS-CoV-2. Nat Microbiol. 5, 536-544 (2020).

67. B. Q. Minh, H. A. Schmidt, O. Chernomor, D. Schrempf, M. D. Woodhams, A. von Haeseler, R. Lanfear, IQ-TREE 2: New Models and Efficient Methods for Phylogenetic Inference in the Genomic Era. Mol. Biol. Evol. 37, 1530-1534 (2020).

68. A. Stamatakis, RAxML version 8: a tool for phylogenetic analysis and post-analysis of 
large phylogenies. Bioinformatics. 30, 1312-1313 (2014).

69. K. Tamura, F. U. Battistuzzi, P. Billing-Ross, O. Murillo, A. Filipski, S. Kumar, Estimating divergence times in large molecular phylogenies. Proc. Natl. Acad. Sci. U. S.

A. $109,19333-19338$ (2012).

70. $\quad$ S. Kumar, G. Stecher, M. Li, C. Knyaz, K. Tamura, MEGA X: Molecular Evolutionary Genetics Analysis across Computing Platforms. Mol. Biol. Evol. 35, 1547-1549 (2018).

71. P. Sagulenko, V. Puller, R. A. Neher, TreeTime: Maximum-likelihood phylodynamic analysis. Virus Evol. 4, vex042 (2018).

72. M. F. Boni, P. Lemey, X. Jiang, T. T.-Y. Lam, B. Perry, T. Castoe, A. Rambaut, D. L. Robertson, Evolutionary origins of the SARS-CoV-2 sarbecovirus lineage responsible for the COVID-19 pandemic, doi:10.1101/2020.03.30.015008. 

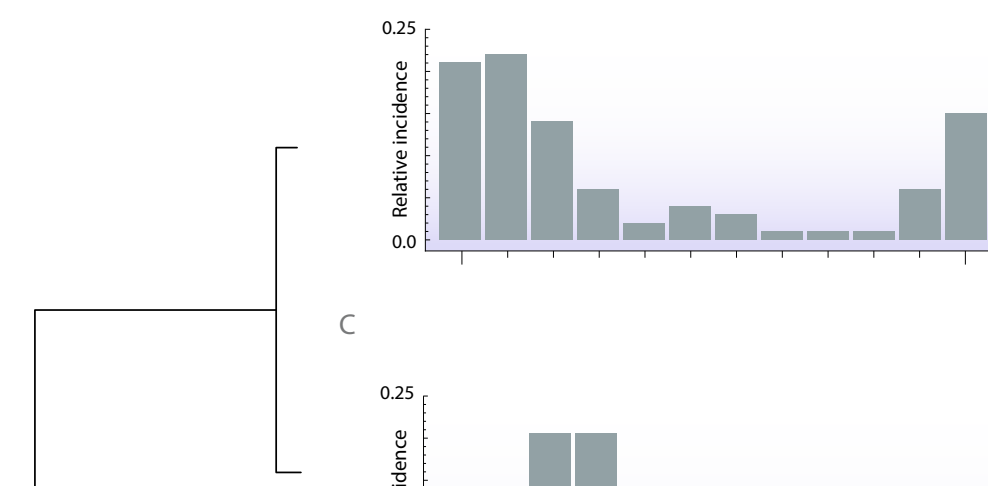

HCoV-NL63

C

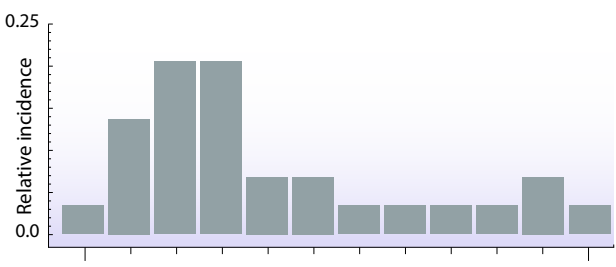

HCoV-229E

D

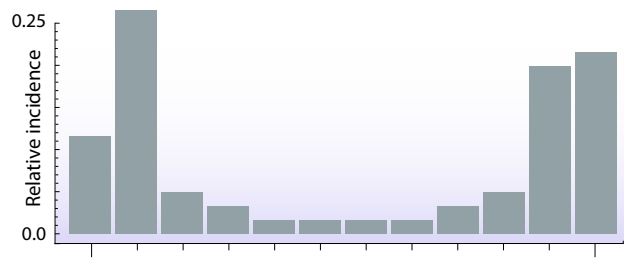

HCoV-HKU1

E

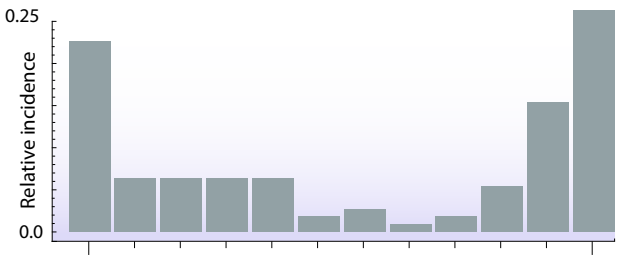

HCoV-OC43

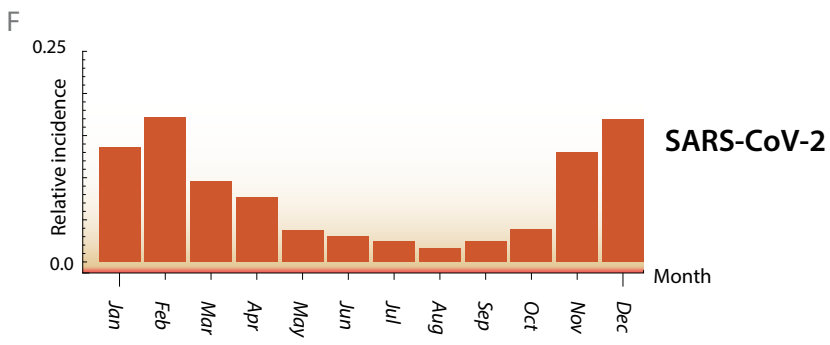


medRxiv preprint doi: https://doi.org/10.1101/2022.01.26.22269905; this version posted January 28, 2022. The copyright holder for this preprint
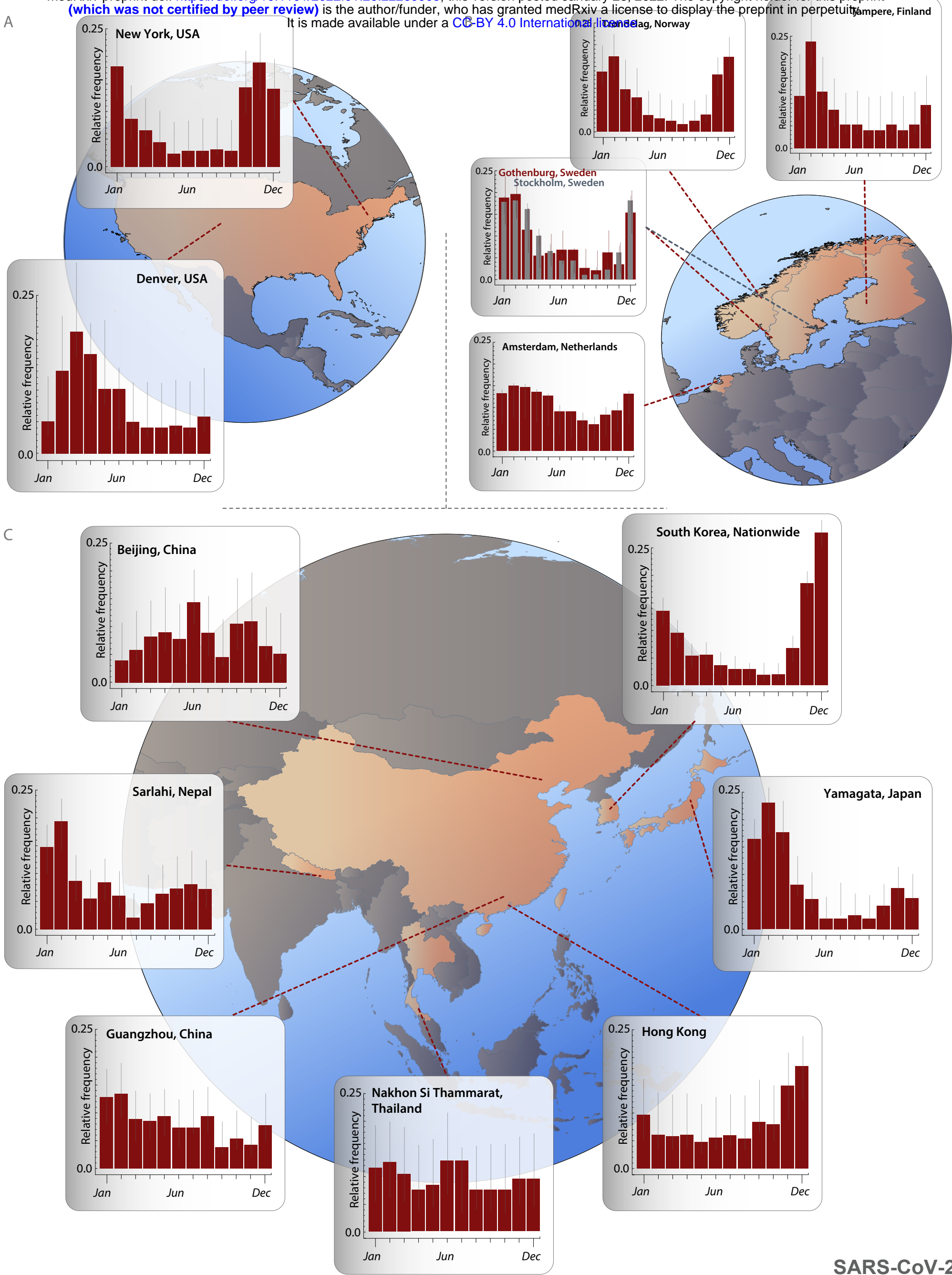